\title{
Evaluation of the application of cashew gum as an excipient to produce tablets
}

\author{
Ana Paula de Sá Pinto ${ }^{1}$, Kattya Giselle de Holanda e Silva and Claudia Regina Elias Mansur ${ }^{1,3 *}$ \\ 'Laboratório de Macromoléculas e Colóides na Indústria do Petróleo, Instituto de Macromoléculas - \\ IMA, Universidade Federal do Rio de Janeiro - UFRJ, Rio de Janeiro, RJ, Brasil \\ ${ }^{2}$ Laboratório de Sistemas Híbridos, Faculdade de Farmácia, Universidade Federal do Rio de Janeiro - \\ UFRJ, Rio de Janeiro, RJ, Brasil \\ ${ }^{3}$ Programa de Engenharia de Materiais e Metalurgia, Centro de Tecnologia, Instituto Alberto Luiz Coimbra \\ de Pós-graduação e Pesquisa de Engenharia - COPPE, Universidade Federal do Rio de Janeiro - UFRJ, \\ Rio de Janeiro, RJ, Brasil \\ *celias@ima.ufrj.br
}

\begin{abstract}
Cashew gum is extracted from the exudate of the giant cashew tree (Anacardium occidentale L.). The objective of this work was to study the extraction and purification of cashew gum through experiments to characterize its structures and physicochemical and thermal properties, and to evaluate its use as a pharmaceutical excipient. The characterization of the materials was performed by infrared spectroscopy, thermogravimetric analysis and rheological studies of powder. Analysis of the material showed that it has reasonable flow characteristics and compressibility, allowing the use as diluent of tablets. Tablets were produced with a cashew gum isolated and purified by the direct compression method, and it was shown that the tablets produced with the purified cashew gum obtained better mechanical properties (hardness and friability) and less disintegration time than tablets made with gum of cashew isolated, suggesting the use of purified cashew gum as a diluent for this type of pharmaceutical form.
\end{abstract}

Keywords: cashew gum, pharmaceutical excipient, direct compression, characterization, tablets.

\section{Introduction}

The International Pharmaceutical Excipients Council defines excipients as substances composing pharmaceutical preparations that, although therapeutically inert or inactive, are necessary for their manufacture ${ }^{[1]}$.

Tablets are one of the main forms for oral administration of solid drugs. They are easy to administer and can contain one or multiple drugs. They are prepared with pharmaceutical excipients that facilitate compression during manufacture and guarantee suitable mechanical properties for disintegration and drug release within the body ${ }^{[2]}$. They can be produced by compression of powders obtained by wet or dry granulation or by direct compression. In the direct compression method, the mixture of powders is compressed without a prior granulation step, reducing the number of steps on the production line and hence the time and $\cos ^{[3]}$.

The cashew gum from Northeastern Brazil is characterized as a branched heteropolysaccharide acid, which after hydrolysis is basically composed of $\beta$-D-galactose (72\%), D-glucose (14\%), arabinose (4.6\%), rhamnose (3.2\%) and glucuronic acid $(4.7 \%)^{[4]}$. Cashew gum has been studied by various researchers in a wide range of fields, including the pharmaceutical sector. In this respect, this substance has been investigated for the formation of hydrogels, tablet fillers, mucoadhesive propertis, micro and nanoparticles for controlled drug release ${ }^{[5-8]}$.
Specifically, for production of tablets, cashew gum has been studied as a binder, drug release promoter and former of coating films. All the studies reported in the literature have used the wet granulation method to prepare tablets ${ }^{[6,9-11]}$. Also, no work has investigated the use of this excipient material as a diluent for tablets.

Another factor that deserves mention is the need to standardize the method to obtain any raw material, to assure its quality and safety, especially for medicinal use ${ }^{[1]}$. Previous studies of cashew gum have applied various methods to obtain this material, so there is as yet no standardized method for its extraction. Therefore, the objective of this study was to investigate the variables related to the extraction and purification of cashew gum, as well as the possibility of its use as a diluent excipient for production of tablets by the direct compression method.

\section{Materials and Methods}

We used the following materials: cashew gum exudate, collected in the municipality of Severiano Melo, Rio Grande do Norte, Brazil; hydrated ethyl alcohol $\left(95.54^{\circ} \mathrm{GL}\right)$; sodium chloride $(\mathrm{NaCl})$ reagent grade, sodium hydroxide reagent grade; and spectroscopic potassium bromide $(\mathrm{KBr})$, all acquired from Vetec Química Fina (Brazil). 


\subsection{Extraction and purification of cashew gum}

The following factors were assessed in this respect: sodium chloride $(\mathrm{NaCl})$ concentration; cashew tree exudate concentration in proportion to ethanol $95.54^{\circ} \mathrm{GL}$; and number of purification steps.

\subsubsection{Determination of the best $\mathrm{NaCl}$ concentration}

Initially the best salt content was evaluated for subsequent use in planning the experiments to evaluate the other factors (concentrations of gum and ethanol). To assess the influence of $\mathrm{NaCl}$ concentration, four aqueous solutions were prepared containing $10 \% \mathrm{w} / \mathrm{v}$ of unprocessed (in natura) gum (exudate), which were submitted to magnetic stirring for 24 hours. After this period, the $\mathrm{pH}$ of each solution was adjusted to $\mathrm{pH} 7$ with sodium hydroxide $1 \mathrm{M}(\mathrm{NaOH})$. Then, in each $100 \mathrm{~mL}$ of gum solution, varied quantities of $\mathrm{NaCl}$ were added $(3,5,7$ and $9 \mathrm{~g})$, to obtain solutions called gum- $\mathrm{NaCl} 3 \%, 5 \%, 7 \%$ and $9 \% \mathrm{w} / \mathrm{v}$. These were stirred until the salt was completely dissolved. Then the solutions were centrifuged to remove sand and other solids. The resulting solutions were filtered through a sintered disk funnel with porosity 1 . The gum was extracted by precipitation using ethanol $95.54^{\circ} \mathrm{GL}$ as non-solvent agent, in the ratio of $4: 1$ (ethanol:gum solution). After precipitation, the mixture was again centrifuged to separate the precipitate from the hydroalcoholic solution.

The precipitate was frozen and lyophilized and then ground with a mortar to obtain a powder. The isolated cashew gum (ICG) was then purified, by repeating the same routine as in the first step, but without adjusting the $\mathrm{pH}$ and adding salt. The amount of salt that will be used in the next steps will be chosen according to the evaluation of the yield obtained at the end of the purification process verified in this topic.

After the purification, the cashew gum (CG) was washed to remove a possible excess salt, as described below (performed in duplicate).

In each centrifuge tube (1, 2 and 3), $2 \mathrm{~g}$ of sample (ground CG) and $20 \mathrm{~mL}$ of ethanol were added. The tubes were shaken to assure contact of the ethanol with the gum particles. Then the tubes were spun at $4,000 \mathrm{rpm}$ for $5 \mathrm{~min}$. For tube 1 this process was performed once only. For tube 2, the ethanol was discarded and $20 \mathrm{~mL}$ of fresh ethanol was added, followed by the same centrifuging, for two washing steps. For tube 3, the same process was repeated a third time, to complete three washing steps. At the end of the process, the remaining material in each tube after discarding the ethanol (supernatant) was frozen with liquid nitrogen and lyophilized until complete drying of the sample (24 hours). All the samples were ground, and identified as: tube 1- PCGW1, with one washing; tube 2- PCGW2, with two washings; and tube 3- PCGW3, with three washings.

At the end, each sample was ground in an analytic mill (model IKA ${ }^{\circledR}-$ WORKS A11 basic) for 2 minutes. The resulting isolated and purified gum powders were analyzed by thermogravimetry (TGA) in a TA Instruments TGA Q500 analyzer, using a heating rate of $10{ }^{\circ} \mathrm{C} / \mathrm{min}$ in a range between $0^{\circ}$ and $700{ }^{\circ} \mathrm{C}$, under an inert nitrogen atmosphere.
2.1.2 $22^{2}$ Factorial design with center point repetitions to study the extraction of cashew gum

The influence of the exudate and ethanol concentrations on the extraction yield was studied using a $2^{2}$ factorial design. For this purpose, cashew tree exudate solutions were prepared in distilled water at concentrations of $5,7.5$ and $10 \% \mathrm{w} / \mathrm{v}$ (low, level and high level, respectively) at $\mathrm{pH}$ 7. Then $\mathrm{NaCl}$ was added to reach a salt concentration of $7 \% \mathrm{w} / \mathrm{v}$ in the samples, which were centrifuged and then filtered through a sintered glass disk funnel. The filtrate was submitted to precipitation with ethanol at proportions of ethanol:CG solution of 4:1, 6:1 and 8:1 (low, level and high level, respectively).

Based on the results of the tests described above, it was necessary to perform complementary experiments, varying the exudate concentration (4.0 to $10.0 \% \mathrm{w} / \mathrm{v}$ ) while keeping the ethanol proportion constant $(4: 1)$, to try to obtain the best results.

\subsubsection{Obtaining purified cashew gum}

The purified cashew gum (PCG), used in the other steps, was obtained under the following extraction and purification conditions, selected based on the factorial experiments described above: $\mathrm{NaCl}$ concentration of $7 \% \mathrm{p} / \mathrm{v}$; exudate concentration in solution of $7.0 \% \mathrm{p} / \mathrm{v}$; ethanol:exudate solution ratio of $4: 1$; and three extraction steps, one for isolation and two for purification.

To check whether the number of extraction steps had an influence on the removal of impurities from the gum, a second purification step was performed with the gum sample obtained after the first purification step, following the same procedures as in the first step.

\subsection{Fourier-Transform Infrared absorption spectroscopic analysis}

The chemical structure of the cashew gum was characterized by spectroscopy in the mid-infrared region of 4000 to $400 \mathrm{~cm}^{-1}$, in a Varian Excalibur spectroscope. The spectra were obtained by mixing the material with potassium bromide $(\mathrm{KBr})$ in pellet form, using 50 scans and resolution of $2 \mathrm{~cm}^{-1}$.

\subsection{Thermogravimetric analysis}

The TGA of the purified gum was performed with a TA Instruments TGA Q500 analyzer, using a heating rate of $10{ }^{\circ} \mathrm{C} / \mathrm{min}$ in the range from $0{ }^{\circ} \mathrm{C}$ to $700{ }^{\circ} \mathrm{C}$ under an inert nitrogen atmosphere.

\subsection{Rheological testing of the powder}

The rheological tests of the purified cashew gum powder involved measuring the average particle size, along with the angle of repose and the bulk (or apparent) and tapped (or compacted) densities, to determine the flow properties. These density values were used to determine the Carr index and Hausner ratio.

\subsubsection{Determination of the average particle size}

For the verification of the average particle size, the apparatus "Bertel electromagnetic stirrer 110/220v with 6 screens" was used by means of the granulometric analysis described in Agência Nacional de Vigilância Sanitária ${ }^{[12]}$. 
2.4.2 Angle of repose, Carr index and Hausner ratio and Flow properties

The angle of repose was determined according to the method described by Aulton ${ }^{[13]}$. The Carr index and the Hausner ratio were obtained by using the density values of the gum samples, following the method described by British Pharmacopeia ${ }^{[14]}$. These parameters for the purified gum powder were compared with those values published in British Pharmacopeia ${ }^{[14]}$ to indicate the flow properties.

\subsection{Production of tablets}

After the tests of the purified powers, tablets were produced and their properties were evaluated by the method described below.

\subsubsection{Preparation of the tablets}

The tablets were prepared by direct compression of the purified powder. For each tablet, a powder mass of approximately $350 \mathrm{mg}$ was weighed and compressed manually in a Lemaq LM-1 Monopress, with single punch and using a spherical matrix having diameter of $13 \mathrm{~mm}$, applying 3 metric tons of pressure.

\subsubsection{Evaluation of average weight and mechanical strength}

The tests to determine the average weight and mechanical strength (hardness and friability) and disintegration period were performed according to the method described Agência Nacional de Vigilância Sanitária ${ }^{[12]}$.

\section{Results and Discussions}

\subsection{Extraction and purification of cashew gum}

The purpose of studying the method of extraction and purification of the cashew gum was to ascertain the factors that influence the yield and degree of purity. These factors were chosen due to their relevance, as presented in previous articles ${ }^{[4,15-17]}$, according to which it is necessary to establish a reproducible method of extraction and purification of this material.

Initially, it was analyzed the effect of the concentration of $\mathrm{NaCl}$ in the aqueous solution prepared to dissolve the cashew tree exudate. Besides, the experiments was conduced to assess the influence of initial exudate mass and proportion of ethanol used to extract and purify the gum.

\subsubsection{Determination of the best $\mathrm{NaCl}$ concentration}

According to Costa et al. ${ }^{[15]}$, the addition of $\mathrm{NaCl}$ in excess in a previously neutralized aqueous solution of cashew gum enables the substitution of the cations possibly contained in the exudate $\left(\mathrm{K}^{+}, \mathrm{Ca}^{2+}, \mathrm{Mg}^{2+}, \mathrm{Fe}^{3+}\right)$ by $\mathrm{Na}^{+}$, favoring its transformation into sodium salt. This transformation is reflected in an increase of the gum's solubility in aqueous solutions: at $\mathrm{NaCl}$ concentrations of 3, 5,7 and $9 \%$ the final yield was 58.16, 63.93, 75.56 and $76.10 \%$, respectively. As can be seen, higher $\mathrm{NaCl}$ concentrations promoted increased solubility of the solutions containing the exudate, leading to higher final yield of the process.

To validade the method of extracting the cashew gum (CG) was employed the $\mathrm{NaCl}$ concentration of $7 \% \mathrm{w} / \mathrm{v}$ to obtain a gum with higher solubility, particle size uniformity and high degree of purity.

\subsection{2 $2^{2}$ factorial experiments to evaluate the cashew gum extraction conditions}

Table 1 shows the yields in the $2^{2}$ factorial experiments, with three repetitions at the center point.

As shown by Table 1, the highest yields were obtained in experiments 1 and 3 , where the exudate concentration was low level and the ethanol concentration was at both levels. This suggests that the gum concentration has a significant influence on the extraction yield. To corroborate this hypothesis, we performed statistical analysis using the Statisca 7.0 program to analyze the results shown in Table 2.

Table 2 and Figure 1 report the values of the coefficients associated with the two independent variables, along with their interaction. Only the exudate concentration had a significant influence, since the $p$-value obtained is lower than 0.05 .

Table 1. Results of the factorial design $2^{2}$.

\begin{tabular}{cccc}
\hline Samples & $\begin{array}{c}\text { Concentration } \\
\text { exudate(\%) }\end{array}$ & $\begin{array}{c}\text { Ethanol:Solution } \\
\text { exudate }\end{array}$ & $\begin{array}{c}\text { Yield } \\
\mathbf{( \% )}\end{array}$ \\
\hline 1 & -1 & -1 & 75.64 \\
2 & 1 & -1 & 66.61 \\
3 & -1 & 1 & 76.48 \\
4 & 1 & 1 & 64.54 \\
5 & 0 & 0 & 71.68 \\
6 & 0 & 0 & 70.69 \\
7 & 0 & 0 & 70.59 \\
\hline
\end{tabular}

Table 2. Regression coefficients.

\begin{tabular}{cccccc}
\hline $\begin{array}{c}\text { Regression } \\
\text { Coefficient }\end{array}$ & $\boldsymbol{\beta}_{\mathbf{0}}$ & $\boldsymbol{\beta}_{\mathbf{1}}$ & $\boldsymbol{\beta}_{\mathbf{2}}$ & $\boldsymbol{\beta}_{\mathbf{1 2}}$ & $\begin{array}{c}\text { Model } \\
\text { adjustment } \\
\text { missing }\end{array}$ \\
\hline value & 70.89 & -5.24 & -0.31 & -0.73 & - \\
$\boldsymbol{P}$ & 0.00001 & 0.003289 & 0.411646 & 0.137846 & 0.744946 \\
\hline
\end{tabular}

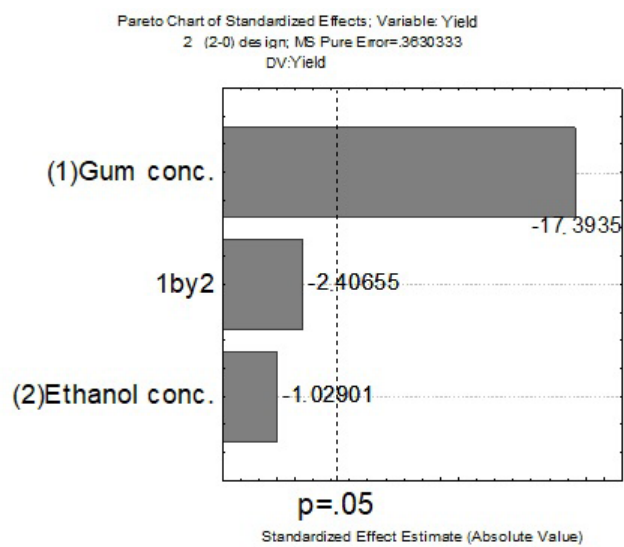

Figure 1. Diagram of Pareto for each independent factor and interaction in factorial design $2^{2}$. According to the figure, only the concentration of the gum is a significant factor to the process. 
As shown in Table 2, of the variables analyzed, only gum concentration presented a statistically significant influence. The negative value of the associated regression coefficient $\left(\beta_{1}\right)$ indicates it is best to work with the lowest concentration and that neither the ethanol concentration nor the interaction between the resin and ethanol concentrations was statistically significant. However, the value near zero of the regression coefficient $\left(\beta_{2}\right)$ associated with the ethanol concentration also indicates it is better to work with the medium ethanol concentration or with the lowest concentration value.

Based on the general mathematical model represented in Equation 1 for the $2^{2}$ factorial design, it is possible to write a predictive model obtained from analysis of the experimental results, as presented in Equation 2.

$$
\begin{aligned}
& Y=\beta_{0}-\beta_{1} X_{1}-\beta_{2} X_{2}-\beta_{12} X_{1} X_{2} \\
& Y=70.89-5.24 X_{1}
\end{aligned}
$$

After verifying the significant influence of gum concentration, we performed complementary experiments varying this concentration and keeping the ethanol:solution ratio constant at $4: 1$. Figure 2 shows the results with gum concentrations from $4 \%$ to $10 \% \mathrm{w} / \mathrm{v}$.

The results shown in Figure 2 indicate that the greatest purified gum yield was obtained at an exudate concentration in the solution of $7 \% \mathrm{w} / \mathrm{v}$. The inflection point of the curve of concentration vs. yield represented in Figure 2 is $7 \%$. As of this concentration, the yield of the CG extraction process started to decline, indicating a saturation point of the system exists.

\subsection{Fourier -Transform Infrared Spectroscopy (FTIR)}

The FTIR spectrum presented in Figure 3 has two cashew gum bands, as described in the literature Silva et al. ${ }^{[17]}$. The following bands can be observed: an intense band in the range from 3398 to $3392 \mathrm{~cm}^{-1}$, which can be attributed to the stretching vibration of the hydroxyl-OH group, typical of polysaccharides; a small band from 2927 to $2928 \mathrm{~cm}^{-1}$, referring to the stretching vibration of the $\mathrm{C}-\mathrm{H}$ groups, related to the monosaccharide galactose; a band from 1643 to $1613 \mathrm{~cm}^{-1}$, which can be attributed to the O-H group from the scissoring vibration of water molecules of residual carboxyl groups of glucuronic acid; and a broad and intense band from 1078 to $1080 \mathrm{~cm}^{-1}$, referring to the stretching of the $\mathrm{C}-\mathrm{O}-\mathrm{C}$ group from the glycosidic bonds of the sugars and stretching and bending vibrations of the $\mathrm{O}-\mathrm{H}$ bond of the pyranoside sugars present in the chain of this gum.

\subsection{Thermogravimetric analysis}

Table 3 presents the temperatures of each degradation stage of the samples: isolated cashew gum (ICG), purified cashew gum (PCG), purified cashew gum with one washing step (PCGW1), purified cashew gum with two washing steps (PCGW2), and purified cashew gum with three washing steps (PCGW3); as well as the percentage of residual mass of each sample. According to this table, sample ICG had one degradation stage more than the other samples, at a temperature of $180.85^{\circ} \mathrm{C}$. The existence of this additional degradation stage shows that the method used to purify the CG was effective, by removing contamination by plant matter from the gum's sugars, Mothé and Rao ${ }^{[18]}$. The thermographs of the purified CG samples contain three degradation peaks, the first at $48.23{ }^{\circ} \mathrm{C}$, referring to the loss of water, and the second and third, at $232.29^{\circ} \mathrm{C}$ and $295.85^{\circ} \mathrm{C}$, respectively, showing that the decomposition of the polysaccharides of this gum occurs in two stages, confirming the finding reported by Mothé and $\mathrm{RaO}^{[18]}$.

To check whether sample PCG was free of possible excess $\mathrm{NaCl}$ added during the purification process, we performed

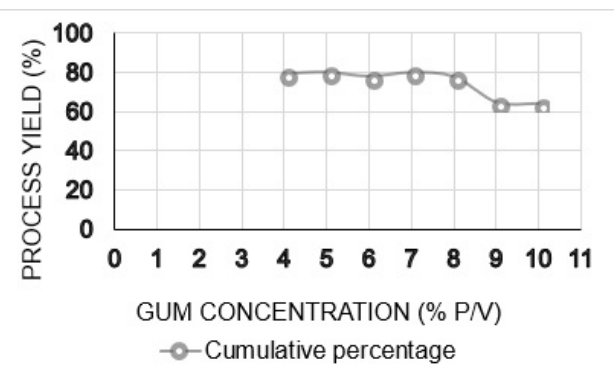

Figure 2. Study the yield of cashew gum. The 7\% concentration is inflection point, where the maximum yield of the curve occurs.

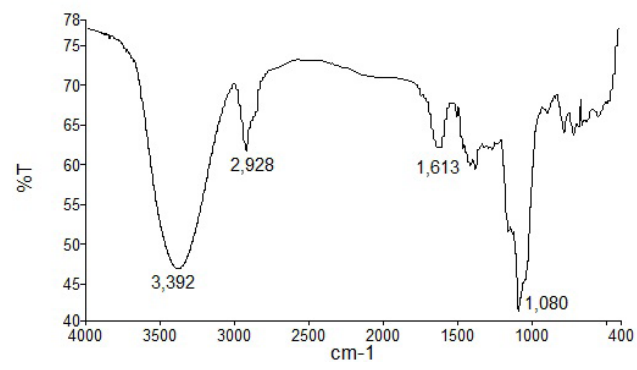

Figure 3. FTIR ( $\mathrm{KBr}$ ) spectrum GC purified.

Table 3. Thermogravimetric analysis.

\begin{tabular}{cccccc}
\hline Samples & $\begin{array}{c}\text { Temperature of the first } \\
\text { degradation stage }\left({ }^{\circ} \mathbf{C}\right)\end{array}$ & $\begin{array}{c}\text { Temperature } \\
\text { in the second } \\
\text { degradation stage }\left({ }^{\circ} \mathbf{C}\right)\end{array}$ & $\begin{array}{c}\text { Temperature } \\
\text { of the third } \\
\text { degradation stage }\left({ }^{\circ} \mathbf{C}\right)\end{array}$ & $\begin{array}{c}\text { Temperature } \\
\text { of the fourth } \\
\text { degradation stage }\left({ }^{\circ} \mathbf{C}\right)\end{array}$ & $\begin{array}{c}\text { Residual } \\
\text { percentage }(\%)\end{array}$ \\
\hline ICG & 53.81 & 180.85 & 227.36 & 292.51 & 19.56 \\
PCG & 48.23 & - & 232.29 & 295.85 & 21.02 \\
PCGW1 & 49.25 & - & 228.29 & 292.81 & 20.57 \\
PCGW2 & 50.55 & - & 227.92 & 292.28 & 19.93 \\
PCGW3 & 48.05 & - & 228.99 & 291.20 & 19.78 \\
\hline
\end{tabular}


three washing steps of the PCG. The thermographs referring to samples PCGW1, PCGW2 and PCGW3 show that it is not necessary to perform washing steps of the PCG, since there were no significant changes in the residual mass percentages at the end for each sample.

\subsection{Rheological properties of the powder}

The following rheological properties of the cashew gum samples were evaluated: average particle size, by granulometry; and compressibility and flow of the isolated and purified gum samples, by measuring the bulk (or apparent) density, tapped (or compacted) density and angle of repose.

\subsubsection{Determination of the average particle size}

The results of this experiment showed that the purified CG sample has varied particle size distribution, as can be observed in Figure 4, which reports the percentages of mass retained in the sieves with different mesh sizes. According to Agência Nacional de Vigilância Sanitária ${ }^{[12]}$, the powder samples had semi-fine profile, because all the particles passed through the $355 \mu \mathrm{m}$ mesh sieve and at most $40 \%$ passed through the $180 \mu \mathrm{m}$ mesh. We found that the average size of the purified CG particles was $253.64 \mu \mathrm{m}$, which can be considered a relatively small size.

\subsubsection{Angle of repose}

Another parameter of the flow behavior of a powder is the angle of repose, which is a measure of the powder's ability of flow through an orifice in a flat surface. It is considered a direct measure ${ }^{[19-21]}$. This is an easy flow measure to obtain because it only requires determining the angle formed between the side of a stationary pile of powdered material and the horizontal. The higher the angle of repose, the more cohesive the powder is.

The static angle of repose was $38^{\circ}$ (base radius $=7 \mathrm{~cm}$ and height $=5.5 \mathrm{~cm}$ ) for the purified gum. This value suggests the sample in question has a reasonable flow property, as described in Hausner ${ }^{[22]}$. The better angle of the purified gum can be related to its smaller average particle size, resulting

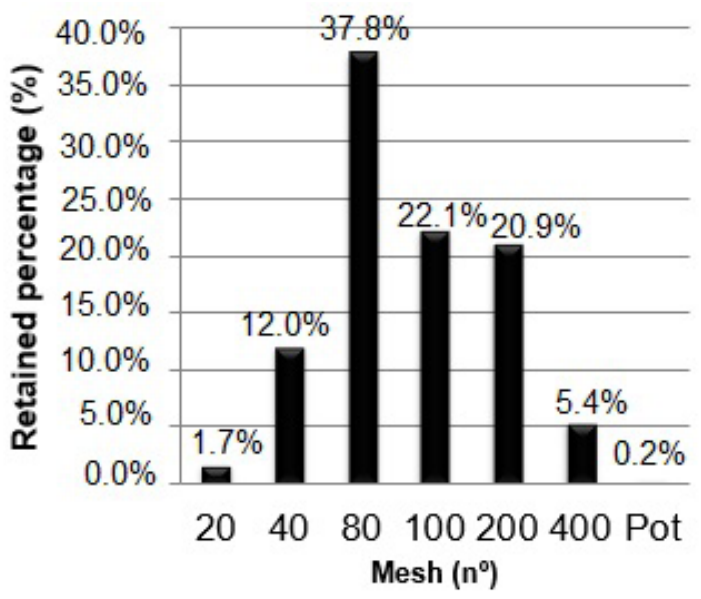

Figure 4. Percentage of mass Purified CG retained in different sizes of mesh sieves. The powder samples had semi-fine profile. in a greater surface area and commensurately stronger cohesion among the particles.

\subsubsection{Carr index and Hausner ratio}

The Carr index and Hausner ratio are similar parameters, also used to assess the flow properties of powdered materials, related to the degree of particle interaction and the compressibility of the sample. They are both based on measurement of the bulk (or apparent) density and tapped (or compacted) density ${ }^{[14,22-24]}$.

The Carr index and Hausner ratio were found by applying the formulas mentioned previously. The values were 19.69 and 1.24 for the Carr index and Hausner ratio of the purified CG, respectively.

\subsubsection{Flow properties of the cashew gum powders}

Knowledge of the flow properties of powders is one of the main objectives of the pre-formulation tests conducted during the development of a product, since this parameter affects the quality of solid pharmaceutical preparations, such as tablets and capsules. This parameter is generally determined before testing the compression of tablets or filling of gelatin capsules. Low fluidity of the raw material can negatively affect hardness, friability and content uniformity of tablets ${ }^{[15]}$.

The flow characteristics of powders can be determined by various techniques, such as measuring the angle of repose and calculating the Carr index and Hausner ratio. These tests allow assessing the interactions of the particles, since their size, size distribution and morphology affect the flow parameters of the material. Particles with large surface areas in relation to volume (smaller particles) and those with irregular surfaces Interact more readily due to electrostatic and friction forces, increasing the flow resistance and diminishing the flow. Small particles with low density and irregular morphology generally have worse flow properties than larger spherical particles with high density ${ }^{[25,26]}$.

Based on the Carr index and Hausner ratio values in correlation with the flow characteristics stipulated in British Pharmacopeia ${ }^{[14]}$, the purified cashew gum has intermediate flow resistance, so it might or might not impair the feed to the compression machine and negatively affect the average weight and hardness of the tablets. However, the angle of repose results showed that the flow characteristics were reasonable. Taken together, the Hausner ratio, Carr index and angle of repose values show that the only negative aspect of the purified cashew gum powder is the relatively high cohesion between particles, suggesting the use of slip agents to improve the flow in the compression machine feeders.

Sliding and lubricating agents are normally used when producing tablets, even for materials with good flow properties, so this is not a limiting factor of the use of cashew gum as a diluent for tablets produced by direct compression.

\subsection{Tablets}

Cashew gum has been investigated by several researchers as an excipient for production of tablets by the wet granulation method. In these works, the cashew gum served as a binding agent of the excipients of the active ingredients, as well as to form films to coat tablett ${ }^{[6,10-13]}$. 


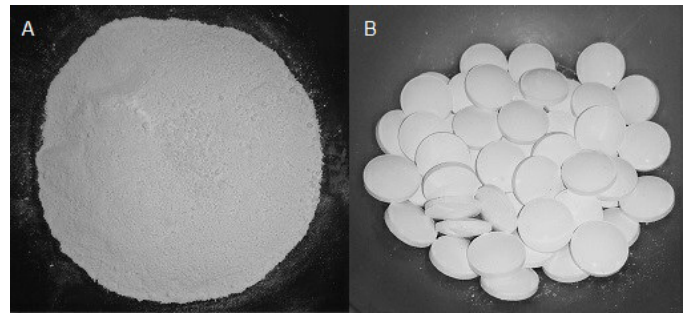

Figure 5. Tablets of purified cashew gum. (A) Powder purified gum; (B) Purified gum tablet.

Figure 5 contains an image of the tablets produced in this study from the purified cashew gum. It is noteworthy that this material in the experimental condition used was suitable for compression.

The tablet pre-formulation tests recommended by the Brazilian Pharmacopoeia are summarized next.

\subsubsection{Evaluation of average weight}

According to Agência Nacional de Vigilância Sanitária ${ }^{[12]}$, the acceptable limits of variation for uncoated tablets with average weight of $250 \mathrm{mg}$ or more is $\pm 5 \%$. The tablets were prepared aiming to obtain a final lot with average weight of $350 \mathrm{mg}$. The results obtained showed that the average weight was well within the acceptable tolerance, since it was $352 \mathrm{mg}$, a positive variation of approximately $0.6 \%$.

\subsubsection{Determination of the mechanical strength of the tablets}

The mechanical strength of the tablets prepared with the isolated and purified cashew gum samples was determined by measuring the hardness and friability.

\subsubsection{Hardness test}

This test is applied mainly to uncoated tablets, allowing assessment of the resistance to crushing or breakage by radial pressure, by simulating falls during manufacture, packaging or transport. The hardness of a tablet is proportional to its compression strength and inversely proportional to its porosity.

According to Agência Nacional de Vigilância Sanitária ${ }^{[12]}$, the minimum hardness acceptable for a tablet is $30 \mathrm{~N}$, or approximately $3 \mathrm{kgf}$. In this study, we evaluated the hardness of 10 tablets made from isolated and purified cashew gum, finding an average hardness of $6.4 \mathrm{kgf}$ and $6.8 \mathrm{kgf}$ respectevely, higher than the minimum threshold set by Agência Nacional de Vigilância Sanitária ${ }^{[12]}$. It should be stressed that the hardness must be sufficiently high to keep the tablets from breaking during production and transport ( $3 \mathrm{kgf}$ ), but not so high as to impair their disintegration in the gastrointestinal tract.

\subsubsection{Friability test}

This test is only applied to uncoated tablets, to determine the resistance to abrasion when subjected to the mechanical action of the measurement device. The percentage of mass loss of the purified gum tablets $(0.17 \%)$ and isolated gum tablets $(0.75 \%)$ was far below the maximum limit stipulated by Agência Nacional de Vigilância Sanitáriaa ${ }^{[12]}$ of $1.5 \%$. None of the tablets cracked or presented fissures at the end of this test.

\subsubsection{Disintegration test}

According to Agência Nacional de Vigilância Sanitária ${ }^{[12]}$, a material in this test should disintegrate 30 minutes, meaning that after this interval, no residue of the units tested (capsules or tablets) should remain in the device's metal screen, except insoluble fragments of tablet coatings or capsule films. Units that are transformed into a pasty mass are also considered disintegrated, provided they do not have a palpable core.

The disintegration process of the isolated cashew gum occurred in 30 minutes, limited maximum estimated by Agência Nacional de Vigilância Sanitária ${ }^{[12]}$. It is possible to notice that part of the material was soluble in the disintegration water and a large amount of particles was dispersed in the medium, confirming the not complete solubility of all the material isolated in the method of obtaining the cashew gum. However, the disintegration time of the CGP was 10 minutes, ie, three times less than the gum disintegration of the ICG, showing that the purification process favors a solubility of the material and removes insoluble particles from the disintegration process.

Based on the results of this study, we can recommend the use of purified cashew gum as a diluent to make tablets, due to its high solubility in water and low disintegration time.

\section{Conclusions}

To obtain higher yields in the cashew gum extraction process, it was established: exudate concentration in water of $7 \%$, ethanol ratio: $4: 1,7 \mathrm{~g} \mathrm{NaCl}$ solution in $100 \mathrm{ml} 7 \%$ gum solution and two extraction steps (isolation and purification). The result of the FTIR proved the characteristic bands of cashew gum and the thermograms proved the purity of the material. The flow properties of purified cashew gum were found to be reasonable, providing suitable conditions for the use of such material as a diluent of tablets obtained by direct compression, as evidenced by the pharmacopoeial tests performed on tablets in this work.

Therefore, the characterization tests take as a whole show that this gum can be a promising source of raw material in Brazil, especially in light of the abundance of Anacardium occidentale trees. Therefore, new studies should be conducted to adjust the properties of the gum, to add further support to the hypothesis that this gum can be used industrially in the pharmaceutical, food and cosmetics sectors.

\section{Acknowledgements}

We thank the Office to Improve University Personnel (CAPES), of the Ministry of Education and the National Council for Scientific and Technological Development (CNPq) and FAPERJ - Carlos Chagas Filho Foundation for Research Support of Rio de Janeiro.

\section{References}

1. Guazzaroni Jacobs, M., Klug, D. B., Christian Moreton, R., \& Silverstein, I. (2009). Qualification of excipients for use in pharmaceuticals. Chimica Oggi, 27(5), 11-13. Retrieved in 
2016, May 6, from http://cat.inist.fr/?aModele=afficheN\&cp sidt $=22065566$

2. Ofori-Kwakye, K., Mfoafo, K. A., Kipo, S. L., Kuntworbe, N., \& Boakye-Gyasi, M. E. (2016). Development and evaluation of natural gum-based extended release matrix tablets of two model drugs of different water solubilities by direct compression. Saudi Pharmaceutical Journal, 24(1), 82-91. http://dx.doi. org/10.1016/j.jsps.2015.03.005. PMid:26903772.

3. Jivraj, M., Martini, L. G., \& Thomson, C. M. (2000). An overview of the different excipients useful for the direct compression of tablets. Pharmaceutical Science \& Technology Today, 3(2), 58-63. http://dx.doi.org/10.1016/S1461-5347(99)00237-0. PMid:10664574.

4. De Paula, R., Heatley, F., \& Budd, P. M. (1998). Characterization of Anacardiumoccidentale exudate polysaccharide. Polymer International, 45(1), 27-35. http://dx.doi.org/10.1002/(SICI)10970126(199801)45:1<27::AID-PI900>3.0.CO;2-9.

5. Soares, P. A. G., Bourbon, A. I., Vicente, A. A., Andrade, C. A. S., Barros, W. Jr, Correia, M. T. S., Pessoa, A. Jr, \& Carneiroda-Cunha, M. G. (2014). Development and characterization of hydrogels based on natural polysaccharides: Policaju and chitosan. Materials Science and Engineering C, 42, 219-226. http://dx.doi.org/10.1016/j.msec.2014.05.009. PMid:25063113.

6. Gowthamarajan, K., Jawahar, N., Wake, P., Jain, K., \& Sood, S. (2012). Development of buccal tablets for curcumin using Anacardium occidentale gum. Carbohydrate Polymers, 88(4), 1177-1183. http://dx.doi.org/10.1016/j.carbpol.2012.01.072.

7. Cordeiro, M. S. F., Silva, C. M. B., M. Vieira, A. C. Q., Nadvorny, D., de Sá, L. L. F., de Souza, F. R. L., Nunes, L. C. C., da Silva-Filho, E. C., Rolim-Neto, P. J., Veiga, F. B., Ribeiro, A. J., de La Roca Soares, M. F., \& Soares-Sobrinho, J. L. (2017). Biopolymers and pilocarpine interaction study for use in drug delivery systems (DDS). Journal of Thermal Analysis and Calorimetry, 127(2), 1777-1785. http://dx.doi. org/10.1007/s10973-016-5796-9.

8. Dias, S. F. L., Nogueira, S. S., França Dourado, F., Guimarães, M. A., Oliveira Pitombeira, N. A., Gobbo, G. G., Primo, F. L., Paula, R. C., Feitosa, J. P., Tedesco, A. C., Nunes, L. C., Leite, J. R., \& Silva, D. A. (2016). Acetylated cashew gum-based nanoparticles for transdermal delivery of diclofenac diethyl amine. Carbohydrate Polymers, 143, 254-261. http://dx.doi. org/10.1016/j.carbpol.2016.02.004. PMid:27083367.

9. Ofori-Kwakye, K., Asantewaa, Y., \& Kipo, S. L. (2010). Physicochemical and binding properties of cashew tree gum in metronidazole tablet formulations. International Journal of Pharmacy and Pharmaceutical Sciences, 2(4), 105-109. Retrieved in 2016, May 6, from http://www.ijppsjournal.com/ Vol2S upp14/949.pdf

10. Gowthamarajan, K., Kumar, G. K. P., Gaikwad, N. B., \& Suresh, B. (2011). Preliminary study of Anacardium occidentale gum as binder in formulation of paracetamol tablets. Carbohydrate Polymers, 83(2), 506-511. http://dx.doi.org/10.1016/j. carbpol.2010.08.010.

11. Ofori-Kwakye, K., Amekyeh, H., El-Duah, M., \& Kipo, S. L. (2012). Mechanical and tablet coating properties of cashew tree (anacardium occidentale 1) gum-based films. Asian Journal of Pharmaceutical and Clinical Research, 5(Suppl. Suppl 4), 62-68. Retrieved in 2016, May 6, from http://hdl.handle. net/123456789/7113

12. Agência Nacional de Vigilância Sanitária. (2010). Farmacopeia Brasileira. Brasília: Anvisa.
13. Aulton, M. E. (2007). Pharmaceutics: the design and manufacture of medicines. London: Churchill Livingstone.

14. British Pharmacopeia (2012). Retrieved in 2016, May 6, from http://bp2012.infostar.com.cn/Bp2012. aspx?a =display\&id=854

15. Costa, S. M. O., Rodrigues, J. F., \& Paula, R. C. M. (1996). Monitorização do processo de purificação de gomas naturais: Goma do cajueiro. Polímeros: Ciência e Tecnologia, 2, 49-55. Retrieved in 2016, May 6, from http://revistapolimeros.org. br/files/v6n2/v6n2a04.pdf

16. Kumar, R., Patil, M. B., Patil, S. R., \& Paschapur, M. S. (2009). Evaluation of Anacardium occidentale gum as gelling agent in aceclofenac gel. International Journal of Pharm Tech Research, 1(3), 695-704. Retrieved in 2016, May 6, from http://sphinxsai. com/PTVOL3/PT=48,\%20RAVIKUMAR\%20(695-704).pdf

17. Silva, D. A., Maciel, J. S., Feitosa, J. P. A., Paula, H. C. B., \& De Paula, R. C. M. (2010). Polysaccharide-based nanoparticles formation by polyeletrolyte complexation of carboxymethylated cashew gum and chitosan. Journal of Materials Science, 45(20), 5605-5610. http://dx.doi.org/10.1007/s10853-010-4625-y.

18. Mothé, C. G., \& Rao, M. A. (2000). Thermal behavior of gum arabic in comparison with cashew gum. Thermochimica Acta, 357, 9-13. http://dx.doi.org/10.1016/S0040-6031(00)00358-0.

19. Geldart, D., Abdullah, E. C., Hassanpour, A., Nwoke, L. C., \& Wouters, I. (2006). Characterization of powder flowability using measurement of angle of repose. China Particuology, 4(3-4), 104-107. http://dx.doi.org/10.1016/S1672-2515(07)60247-4.

20. Fu, X., Huck, D., Makein, L., Armstrong, B., Willen, U., \& Freeman, T. (2012). Effect of particle shape and size on flow properties of lactose powders. Particuology, 10(2), 203-208. http://dx.doi.org/10.1016/j.partic.2011.11.003.

21. Jallo, L. J., Ghoroi, C., Gurumurthy, L., Patel, U., \& Davé, R. N. (2012). Improvement of flow and bulk density of pharmaceutical powders using surface modification. International Journal of Pharmaceutics, 423(2), 213-225. http://dx.doi.org/10.1016/j. ijpharm.2011.12.012. PMid:22197769.

22. Hausner, H. H. (1967). Friction conditions in a mass of metal powder. International Journal of Powder Metallurgy, 3(4), 7-13. Retrieved in 2016, May 6, from https://www.osti.gov/ biblio/4566075

23. Carr, R. L. (1965). Classifying flow properties of solids. Chemical Engineering (Albany, N.Y.), 72(3), 69-72., Retrieved in 2016, May 6, from http://en.journals.sid.ir/ViewPaper. aspx?ID $=232696$

24. Guo, A., Beddow, J. K., \& Vetter, A. F. (1985). A simple relationship between particle shape effects and density, flow rate and Hausner ratio. Powder Technology, 43(3), 279-284. http://dx.doi.org/10.1016/0032-5910(85)80009-7.

25. Morin, G., \& Briens, L. (2013). The effect of lubricants on powder flowability for pharmaceutical application. AAPS PharmSciTech, 14(3), 1158-1168. http://dx.doi.org/10.1208/ s12249-013-0007-5. PMid:23897035.

26. Shah, R. B., Tawakkul, M. A., \& Khan, M. A. (2008). Comparative evaluation of flow for pharmaceutical powders and granules. AAPS PharmSciTech, 9(1), 250-258. http://dx.doi.org/10.1208/ s12249-008-9046-8. PMid:18446489.

Received: May 31, 2017 Revised: Oct. 11, 2017 Accepted: Dec. 14, 2017 